\title{
RESEARCH PAPER \\ COLUMN STUDIES ON THE REMOVAL OF CHROMIUM FROM WASTE WATER BY MANGO SEED SHELL ACTIVATED CARBON
}

\author{
G. D. Akpen ${ }^{1}$, I. L.Nwaogazie ${ }^{2}$ and T. G. Leton ${ }^{3}$ \\ ${ }^{1}$ Department of Civil Engineering, University of Agriculture, Makurdi, Nigeria \\ e-mail:deliakpen@yahoo.com \\ ${ }^{2,3}$ Department of Civil and Environmental Engineering, University of Port Harcourt, \\ Port Harcourt, Nigeria
}

\begin{abstract}
The effects of time and carbon height on the removal of chromium from wastewater were investigated in fixed down flow adsorption columns containing mango seed shell activated carbon (MSSAC) for the purpose of converting the waste to wealth. The Hutchin's bed depth service time (BDST) model was used to study the columns performance at $10 \%$ and $90 \%$ breakthrough concentrations. The BDST model constants were determined. The BDST equation obtained at flow rate of 1.61l.hr and influent chromium concentration of $3.151 \mathrm{mg} / \mathrm{L}$ was used to predict the adsorbent performance at other flow rates and initial chromium concentrations. Results obtained revealed that there was a gradual decrease in the percentage of chromium adsorbed with time; the percentage adsorbed became zero at 72.33, 467.5 and 572 hours respectively for $3 \mathrm{~cm}$, $3.5 \mathrm{~cm}$ and $4 \mathrm{~cm}$ carbon heights. The breakthrough curves for chromium adsorption deviated from the characteristic $S$-curve for most dynamic studies because $100 \%$ removal of chromium was not attained even at the commencement of the column operation because of the high initial concentration of the adsorbate adopted in this study. It was observed that for a given breakthrough concentration, the service time decreased with increase in both flow rate and initial chromium concentration. Chi-square test performed on the developed BDST models revealed the reliability of the models for the prediction of the columns performance particularly at lower breakthrough concentrations. It was therefore recommended that MSSAC can be used for the removal of chromium from wastewater in adsorption columns; however there is the need for pilot studies on live wastewater to investigate the effect of interference.
\end{abstract}

Keywords: Column Adsorption, Activated carbon, mango seed shells, wastewater, pilot studies

\section{INTRODUCTION}

The sorption capacity of a given sorbent for pollutants is usually determined by carrying out an adsorption isotherm. However, isotherms cannot give accurate scale-up data in fixed or fluidised bed processes, because adsorption in a flow column is not at equilibrium. The optimum operating capacity and contact time must be determined in vivo to decide upon the best column dimensions and the number of units needed for continuous treatment (McKay and Bino, 1990). 
Therefore, for an optimal design of an industrial adsorption process, it is important to have accurate modelling and simulation of the dynamic behaviour of the fixed bed system. Several models have been proposed to predict results for a variety of adsorption systems. These models based on fundamental mass transport mechanisms including external film; pore and surface diffusion require the solution of a number of non-linear partial differential equations which include physical and kinetic parameters. These equations can be solved only by numerical methods that are time consuming and tedious.

By using simplified models, pilot plant testing could be largely used for verification rather than information gathering, saving time and money. The bed depth service time (BDST) model (Hutchins, 1973), mass transfer zone model (Michaels, 1952) and Thomas model (1948) among others offer simplified approach and rapid prediction of adsorber performance.

\section{THEORETICAL-BDST MODEL}

Bohart and Adams (1920) developed a relationship based on surface-reaction-rate theory, which can be used to predict the performance of continuous carbon columns. Hutchins (1973) proposed a simple approach based on Bohart and Adams (1920) model for fixed bed adsorbers to correlate the service time with the process variables. The linearized form of this relationship is given thus (Hutchins, 1973):

$\mathrm{t}=\frac{\mathrm{N}_{0} \mathrm{H}}{\mathrm{C}_{0} \mathrm{M}}-\frac{1}{\mathrm{KC}_{0}} \ln \left(\frac{\mathrm{C}_{0}}{\mathrm{C}_{\mathrm{b}}}-1\right)$

Where:

$\mathrm{t}$ is service time (h) to breakthrough; $\mathrm{N}_{o}$ is adsorption capacity ( $\mathrm{mg}$ solute/l adsorbent); $\mathrm{C}_{o}$ is initial solute concentration $(\mathrm{mg} / \mathrm{L})$; $\mathrm{q}$ is linear flow rate $(\mathrm{m} / \mathrm{h}) ; \mathrm{H}$ is depth of adsorbent bed $(\mathrm{m})$; $\mathrm{k}$ is rate constant of adsorption (1/mg.h) and $\mathrm{C}_{\mathrm{b}}$ is outlet concentration at desired breakthrough level (mg/L).

By plotting $\mathrm{t}$ against $\mathrm{H}$ from experimental data, $\mathrm{N}_{\mathrm{o}}$ can be evaluated from the slope of the graph and $\mathrm{k}$ from the intercept at $\mathrm{t}=0$. The bed depth, which theoretically is just sufficient to prevent concentration in excess of $\mathrm{C}_{b}$ at $t=0$, is defined as the critical bed depth $\left(\mathrm{H}_{\mathrm{o}}\right)$ of the column and is determined from Equation (1) when $\mathrm{t}=0$ thus:

$$
\mathrm{H}_{0}=\frac{\mathrm{g}}{\mathrm{kN}_{0}} \ln \left(\frac{\mathrm{C}_{0}}{\mathrm{C}_{b}}-1\right)
$$

At least nine individual column tests must be conducted to collect the laboratory data required for the Bohart-Adams approach, an expensive and time-consuming task. While with Hutchins modification of Bohart-Adams equation, only three fixed bed tests are required to collect the necessary data instead of nine columns. Another advantage of the Hutchins approach is that, if a value of the slope for one flow rate is obtained, values for other flow rates will be computed by multiplying the original slope by the ratio of the original and new flow rates. The intercept, b, value change is insignificant with respect to changing flow rates. Adjustment for changing initial concentration can also be made as follows (Eckenfelder, 1989):

$$
\begin{array}{r}
\alpha_{2}=\alpha_{1} \frac{C_{1}}{C_{2}} \\
b_{2}=b_{1} C_{c_{1}}\left[\ln \left(\frac{C_{2}}{C_{f}}-1\right)\right] \\
C_{1}\left[\ln \left(\frac{C_{1}}{C_{b}}-1\right)\right]
\end{array}
$$

Where:

$\mathrm{C}_{\mathrm{f}}$ and $\mathrm{C}_{\mathrm{b}}$ are the effluent concentrations with respect to $C_{2}$ and $C_{1}$ respectively. But for a fixed breakthrough effluent concentration, $\mathrm{C}_{\mathrm{f}}=$ $\mathrm{C}_{\mathrm{b}}$. Hence Equation (4) can be used to evaluate $\mathrm{b}_{2}$.

A survey of literature revealed that Zhao and Duncan (1998) produced activated carbon from Azolla filiculoides and used it in fixed-bed adsorption columns for quantitative determination 
of the characteristic process parameters which could then be used for performance comparison and process design for zinc removal. Mazumder et al, (2011) studied the removal of colour, copper and chromium from electroplating wastewater in adsorption columns using materials such as wood charcoal, coconut shell carbon and activated alumina. They reported that activated alumina removed the pollutants better than the other carbons.

Lim et al (2008) studied the adsorption of lead $\left(\mathrm{Pb}^{2+}\right)$, copper $\left(\mathrm{Cu}^{2+}\right)$ and zinc $\left(\mathrm{Zn}^{2+}\right)$ on sawdust in fixed bed columns. They reported that the most favourably sorbed metal, $\mathrm{Pb}^{2+}$, occupied most of the adsorption sites on the sawdust in the column. Therefore, less favourably sorbed metals such as $\mathrm{Cu}^{2+}$ and $\mathrm{Zn}^{2+}$ showed more rapid breakthrough. Also, the slopes of the $\mathrm{Zn}^{2+}$ and $\mathrm{Cu}^{2+}$ curves were steeper than that of the $\mathrm{Pb}^{2+}$ curve.

The removal of chromium from wastewater using Mango seed shell activated carbon (MSSAC) in adsorption columns has not been reported. Chromium exists usually in both trivalent and hexavalent forms in aqueous systems. The two oxidation states of chromium have different chemical, biological and environmental characteristics (WHO, 1988). Chromium (III) is relatively insoluble and is required by microorganisms in small quantities as an essentially trace metal nutrient (Saner, 1980). While Chromium (VI) is of great public health concern because of its toxic effects such as dermatitis, ulceration of the skin, liver and kidney damage in animals and humans. The effective removal of chromium from industrial wastewaters is therefore of great importance. The main sources of chromium wastewater are the industries such as paints and pigments, leather tanning, textile dyeing and electroplating operations.

Benue state is the major producer of mangos in Nigeria and during the harvesting period, which is usually between March and July (depending on the variety), the wastes residue (seeds) which litter the surroundings is of concern to environmental pollution, especially as it relates to solid waste management. When the two mango processing industries under construction become operational, the rate of generation of this waste will increase, likewise the cost of management, particularly at the company sites. Considering the large quantity of mango seeds generated in this area and their low cost, it is reasonable to study this residue as a possible precursor for the production of activated carbon for wastewater treatment. Elemental analysis of Mango Seed Shells revealed high carbon content (Table 1) implying that it is a good material for conversion to activated carbon. The objective of this paper therefore is to investigate the performance of mango seed shell activated carbons on the removal of chromium in fixed bed down flow columns for the purpose of converting the waste to wealth.

\section{MATERIALS AND METHODS}

Chur-kpev, a local variety of mango (Magnifera indica) was used for the production of activated carbons. The mango seeds were sourced from Gboko, Ushongu and Makurdi Local Government Areas of Benue State, air dried and broken to obtain the shells. The shells were thoroughly washed with water to remove any dirt, air dried and cut into sizes of $2-4 \mathrm{~cm}$ for chemical activation by impregnating with $\mathrm{ZnCl}_{2}$ solution. The $\mathrm{ZnCl}_{2}$ solution was prepared by dissolving $50 \mathrm{~g}$ anhydrous zinc chloride in $200 \mathrm{~mL}$ of distilled water. $100 \mathrm{~g}$ of the shells were mixed with the solution, boiled at $100^{\circ} \mathrm{C}$ for 30 minutes, and cooled in air to soak for 24 hours. The activated shells were then airdried. Mixing $50 \mathrm{~g}$ of $\mathrm{ZnCl}_{2}$ with $100 \mathrm{~g}$ of mango seed shells represented impregnation ratio of 1:2 by mass (i.e. one part of anhydrous $\mathrm{ZnCl}_{2}$ to 2 parts of mango seed shells). Impregnation ratio of 1:3 was also investigated. The $\mathrm{ZnCl}_{2}$ activated shells were carbonized in a muffle furnace at $500^{\circ} \mathrm{C}$ for 60 minutes to produce Local 1:2 and Local 1:3 activated carbons. Details of the preparation and characterisation of the Mango seed shell activated carbons have been reported elsewhere (Akpen, 2011; Akpen et al, 2011, Akpen et al, 2014). 
Table 1 : Elemental composition of mango seed shells

\begin{tabular}{llccc}
\hline S/N & Mango Variety & Sulphur (\%) & Carbon (\%) & Nitrogen (\%) \\
\hline 1 & Local (Chur-kpev) & $1.4 \times 10^{-6}$ & 43.05 & 0.67 \\
2 & Dausha & $1.6 \times 10^{-6}$ & 43.63 & 0.89 \\
\hline \multicolumn{2}{l}{ Source: $[$ Akpen, 2012] } & &
\end{tabular}

models were also developed at breakthrough concentrations of $10 \%, 40 \%, 50 \%, 60 \%, 80$ $\%$ and $90 \%$ respectively. The validity of the

Adsorption columns were constructed with Local 1:2 variation of the mango seed shell activated carbon (of particle size 150-300 $\mu \mathrm{m}$ ) as adsorbent to exploit their suitability for industrial application in adsorption columns. The contact time and column height were used as variables. Column experiments were performed in a plastic column of $40 \mathrm{~mm}$ diameter. A known amount (in grammes) of carbon under study was carefully transferred into the plastic column packed with cotton wool at the bottom to prevent the escape of the carbon particles with the effluent The water sample to be treated was poured in a 4 litre capacity plastic container fitted with a tap at the bottom to which a $16 \mathrm{~mm}$ plastic pipe was connected and was led to the top of the column through an elbow. Effluents through the plastic column were collected in a $1000 \mathrm{ml}$ beaker through another $16 \mathrm{~mm}$ plastic pipe with a connected tap to regulate the flow. In order to yield different bed heights, $15 \mathrm{~g}, 18 \mathrm{~g}$ and $21 \mathrm{~g}$ of MSSAC were added to produce $3 \mathrm{~cm}, 3.5 \mathrm{~cm}$ and $4 \mathrm{~cm}$, respectively. Before application of the water to be treated to the columns, distilled water was passed through the columns to ensure close packing of the carbon particles. The flow through the columns was by gravity. Efforts were made to keep the pressure head at the desired level above the carbon in the column for all the experimental runs. Lot volumes were collected separately at predetermined time intervals and analysed for residual chromium concentration using Inductively Coupled Plasma (ICP).

\section{Data Analysis}

The result obtained from the column studies was used to plot breakthrough curves. BDST models was verified using Chi-square $\left(\chi^{2}\right)$ test according to equation 5 :

$\chi^{2}=\frac{(0-E)^{2}}{E}$

Where, $\mathrm{O}$ is the observed service time of the column and $\mathrm{E}$ is the predicted service time of the column using the developed BDST models.

\section{RESULTS AND DISCUSSION}

Effect of time and bed height on the removal of chromium from wastewater

The effect of time on the effluent chromium concentration and percentage chromium adsorbed at the bed height of $3 \mathrm{~cm}$ is shown in Fig.1. The fig. indicates a gradual decrease in the percentage adsorbed with time until the percentage adsorbed became zero at about 72.33 hours. A similar trend was observed using bed heights of $3.5 \mathrm{~cm}$ and $4 \mathrm{~cm}$ respectively (see Figs. 2 and 3). The observed trend shows that as the adsorption process continued in the column, the active sites of the adsorbent were gradually saturated leading to lesser amount of chromium adsorbed with time.

With respect to bed height, it was observed that percentage chromium removal was significantly affected by bed height (see Figs 1-3). At operation time of five (5) hours for instance, the percentage adsorbed increased from $52.3 \%$ to $69.1 \%$, when the bed height increased from $3 \mathrm{~cm}$ to $4 \mathrm{~cm}$. This increase in percentage adsorbed is expected because the surface area available for adsorption increased with increase in the amount of the adsorbent because more binding sites were available for sorption with increase in bed height. 


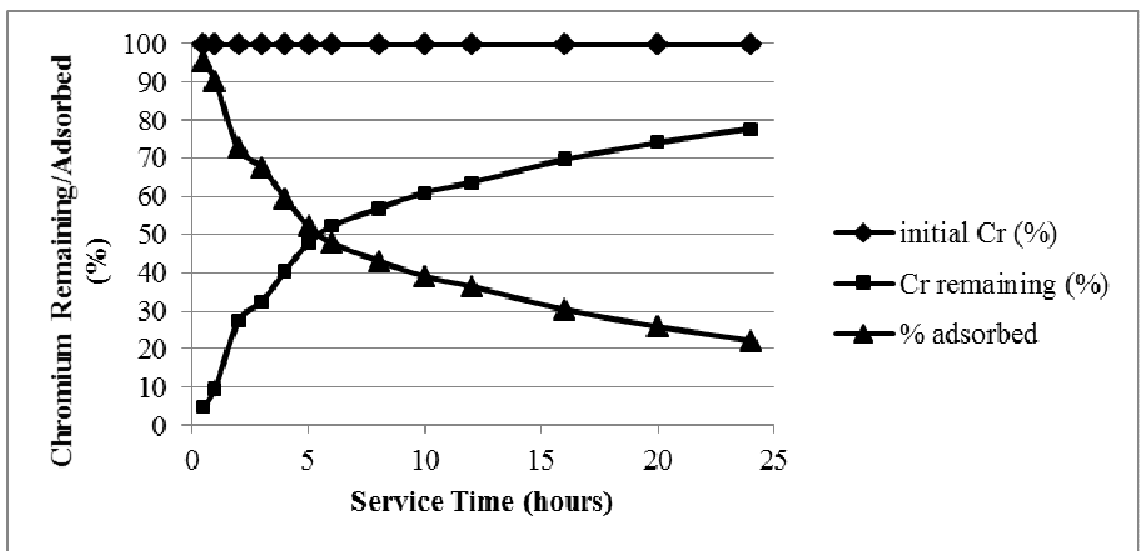

Fig. 1: Effect of time on chromium adsorption at bed height of $3 \mathrm{~cm}$ $($ Carbon $=$ Local 1:2, initial chromium $=3.151 \mathrm{mg} / \mathrm{L})$

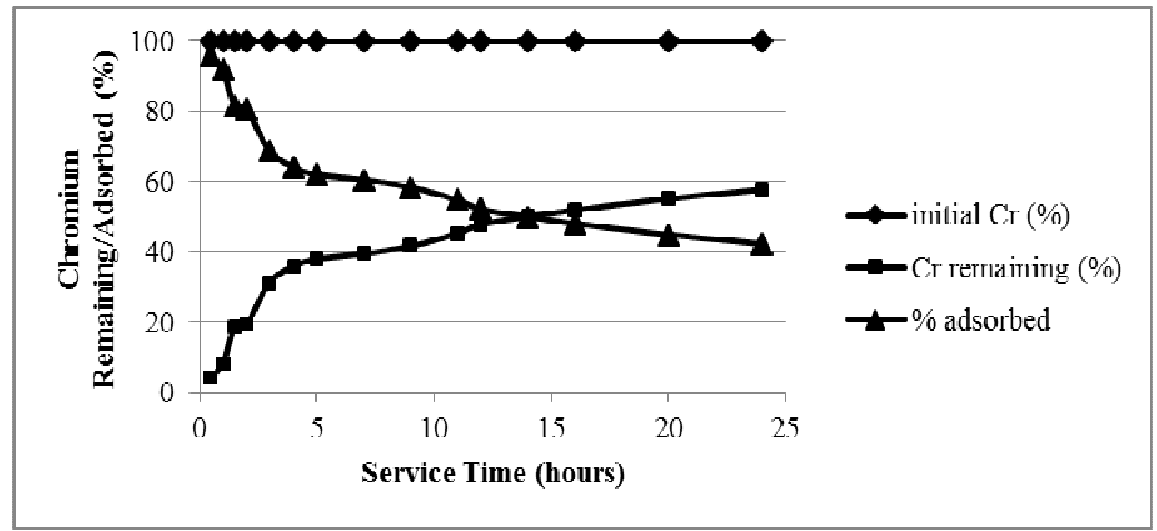

Fig. 2: Effect of time on chromium adsorption at bed height of $3.5 \mathrm{~cm}$ ( carbon $=$ Local 1:2, initial chromium $=3.151 \mathrm{mg} / \mathrm{L}$ )

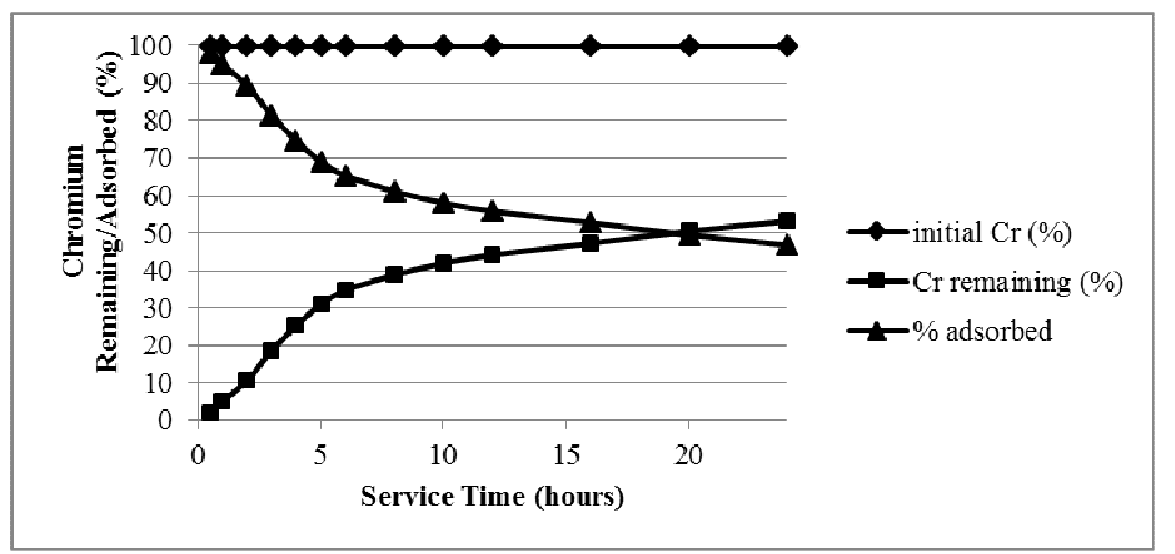

Fig. 3 :Effect of time on chromium adsorption at bed height of $4 \mathrm{~cm}$ $($ Carbon $=$ Local 1:2, initial chromium $=3.151 \mathrm{mg} / \mathrm{L})$ 


\section{Column breakthrough curves}

The most important criterion in the design of fixed bed adsorption systems is the prediction of column breakthrough, which determines the operating life-span of the bed and regeneration times. The adsorption breakthrough curves obtained by varying the bed heights from 3 to 4 $\mathrm{cm}$ at constant pressure head of $28 \mathrm{~cm}$ and initial chromium concentration of $3.151 \mathrm{mg} / \mathrm{L}$ are given in Figs.4-6. The curves were obtained by plotting the dimensionless concentrations, $\mathrm{C}_{\mathrm{t}} / \mathrm{C}_{\mathrm{o}}$ against the service times. These breakthrough curves deviate from the characteristic S-shape for most dynamic adsorption studies in water and waste water treatment. This is probably because $100 \%$ removal of chromium was not attained even at the commencement of the column operation which may be due to the high initial concentration of chromium adopted in this study. Mazumder et al (2011) reported a similar deviation on the adsorption of chromium by activated alumina.

The breakthrough and exhaustion points were assumed as $10 \%(0.3151 \mathrm{mg} / \mathrm{L})$ and $90 \%$ $(2.8359 \mathrm{mg} / \mathrm{L})$ of the initial influent concentration respectively. As shown in the figures, the exhaustion time increased with increasing bed height, from 44.17-290.45 hours as more adsorption sites available for sorption, also resulted in a broadened mass transfer zone. As the feed solution continued to pass through the adsorbent bed, the carbon adsorption sites continued to reduce, and this lead to increase in the concentration of chromium in the effluent with time. At the bed depth $3 \mathrm{~cm}$ for instance, breakthrough and exhaustion points were reached after 1.022 hours and 44.17 hours respectively.

\section{BDST plots}

The breakthrough data obtained from the column studies was examined using the BDST model (Equation 1). The plots of service time (t) against bed depth $(\mathrm{H})$ at $10 \%$ and $90 \%$ breakthroughs are shown in Figs. 7 and 8 respectively. The BDST models at various breakthrough concentrations and their corresponding constants are listed in Table 2. The service time percentage increased, the BDST rate constant, $\mathrm{K}_{\mathrm{a}}$ decreased while the adsorption capacity of the bed per unit bed volume, $\mathrm{N}_{\mathrm{o}}$, and the critical bed depth, $\mathrm{H}_{0}$, increased. The high values of the coefficient of determination, $\mathrm{R}^{2}(0.804$ and 0.916 respectively at $10 \%$ and $90 \%$ breakthrough for instance), indicated the validity of BDST model for the present system.

To confirm the validity of the developed BDST models, a chi-square test was performed (see Table 4). It is obvious from Table 4 that all the models (except $80 \%$ and $90 \%$ breakthrough models) were reliable for the prediction of the columns performance given that, the calculated $\chi^{2}$ values were less than the tabulated values both at $5 \%$ and $1 \%$ levels of significance.

As mentioned earlier, the BDST model constants can be helpful to scale up the process for other flow rates and concentrations without further experimental run (Tables 5 and 6). The use of BDST model in this way provides a realistic description of the adsorption of chromium by MSSAC and the empirical data can be adopted in predicting the bed depth or service time for a specified set of influent characteristics for the scale-up of the adsorption column thus saving time, money and energy that would have been expended in carrying out experiments. The use of BDST plots for column design is illustrated in the next section.

\section{Design of prototype adsorption column}

As an illustration, we adopt the $10 \%$ breakthrough concentration BDST model for the design. Its important to note that the breakthrough concentration depends on the desired effluent quality and may be fixed by a pollution control regulation authority such as National Environmental Standards and Regulatory Agency (NESRA) in Nigeria. Suppose a hypothetical industry discharges $1000 \mathrm{~m}^{3} / 8$-hour day of wastewater containing $3.151 \mathrm{mg} / \mathrm{L}$ of chromium which has to be treated before discharge into a receiving stream. The design is accomplished as follows:

The established BDST model for $10 \%$ break 


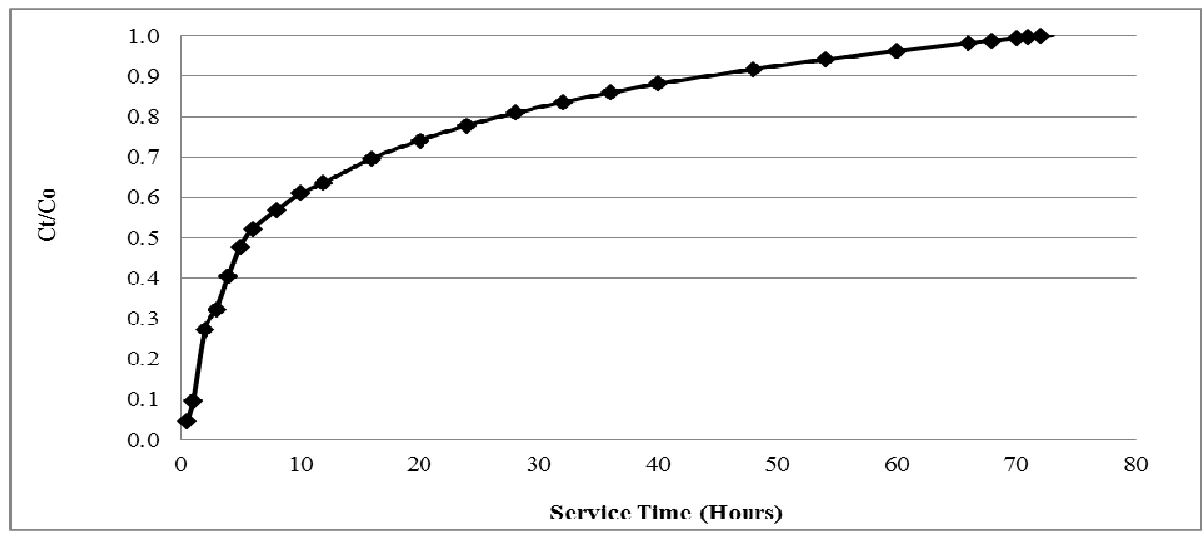

Fig. 4 : Breakthrough curve for chromium adsorption on MSSAC columns with composite wastewater at $3 \mathrm{~cm}$ bed height (initial chromium concentration $=3.151 \mathrm{mg} / \mathrm{L}, \mathrm{pH}=6.5$, pressure head $=28 \mathrm{~cm}$ )

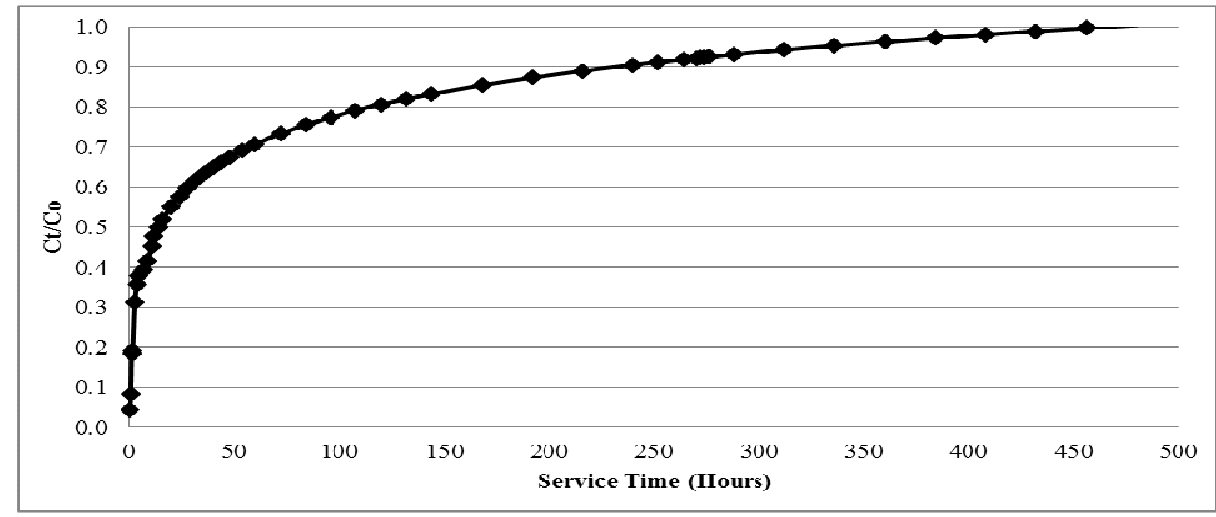

Fig. 5: Breakthrough curve for chromium adsorption on MSSAC columns with composite wastewater at 3.5 cm bed height (initial chromium concentration $=3.151 \mathrm{mg} / \mathrm{L}, p H=6.5$, pressure head $=28 \mathrm{~cm}$ )

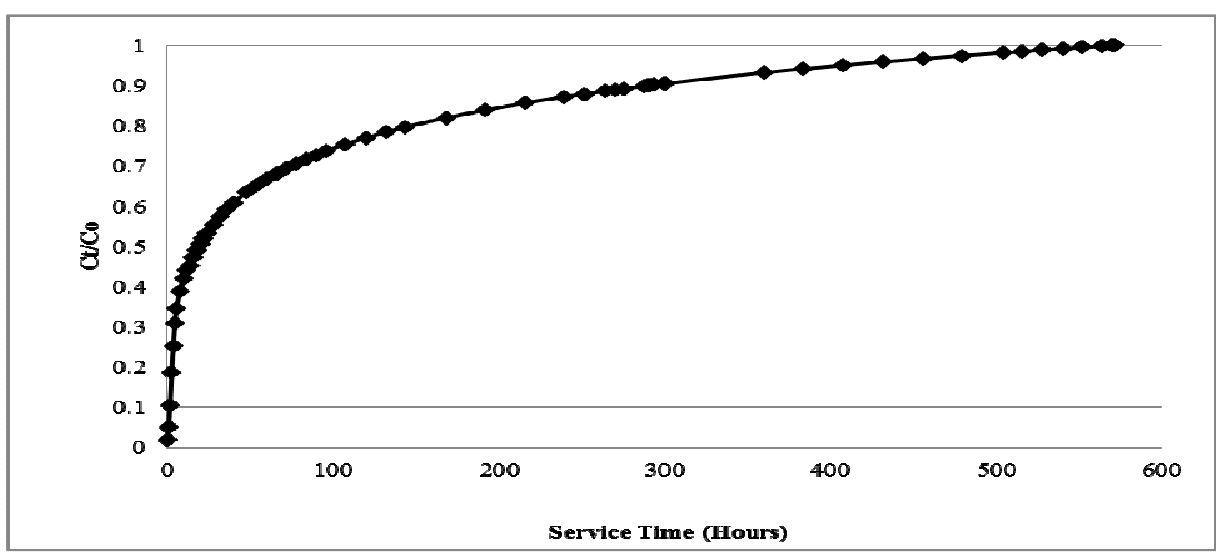

Fig. 6 : Breakthrough curve for chromium adsorption on MSSAC columns with composite wastewater at $4 \mathrm{~cm}$ bed height (initial chromium concentration $=3.151 \mathrm{mg} / \mathrm{L}, p H=6.5$, pressure head $=28 \mathrm{~cm}$ ) 
Table 2 : BDST model parameters

\begin{tabular}{ccccccc}
\hline$\%$ & BDST model & $\begin{array}{c}\mathbf{N}_{\mathbf{o}} \\
(\mathbf{m g} / \mathbf{L})\end{array}$ & $\begin{array}{c}\mathbf{k}_{\mathbf{a}} \\
(\mathbf{L} / \mathbf{m g} . \mathbf{h})\end{array}$ & $\begin{array}{c}\text { Flow rate } \\
(\mathbf{L} / \mathbf{h})\end{array}$ & $\mathbf{H}_{\mathbf{o}}(\mathbf{m})$ & $\mathbf{R}^{\mathbf{2}}$ \\
\hline 10 & $\mathrm{t}=0.883 \mathrm{H}-1.752$ & 3.564 & 0.398 & 1.61 & 1.984 & 0.804 \\
40 & $\mathrm{t}=4.9 \mathrm{H}-10.38$ & 19.78 & 0.0124 & 1.61 & 2.118 & 0.938 \\
50 & $\mathrm{t}=13.81 \mathrm{H}-35.41$ & 55.743 & 0 & 1.61 & 0 & 0.983 \\
60 & $\mathrm{t}=28.57 \mathrm{H}-74.71$ & 115.321 & -0.0017 & 1.61 & 2.649 & 0.968 \\
80 & $\mathrm{t}=121.5 \mathrm{H}-328.6$ & 490.426 & -0.0013 & 1.61 & 2.785 & 0.936 \\
90 & $\mathrm{t}=246.2 \mathrm{H}-673.1$ & 993.77 & -0.0010 & 1.61 & 2.832 & 0.916 \\
\hline
\end{tabular}

Table 3: Observed and predicted service times at various breakthrough concentrations

\begin{tabular}{lllllllllllll}
\hline $\begin{array}{l}\mathbf{H} \\
(\mathbf{m})\end{array}$ & $\mathbf{1 0} \%$ & & $\mathbf{4 0} \%$ & & $\mathbf{5 0} \%$ & & $\mathbf{6 0} \%$ & \multicolumn{8}{c}{$\mathbf{8 0 \%}$} & \multicolumn{3}{c}{$\mathbf{9 0 \%}$} \\
& Obs. & Pred. & Obs. & Pred. & Obs. & Pred. & Obs. & Pred. & Obs. & Pred. & Obs. & Pred. \\
\hline $\mathbf{3}$ & 1.022 & 0.017 & 3.95 & 4.32 & 5.51 & 6.02 & 9.52 & 11 & 26.81 & 35.9 & 44.17 & 65.5 \\
$\mathbf{3 . 5}$ & 1.086 & 0.048 & 7.49 & 6.77 & 13.99 & 12.93 & 28.24 & 25.29 & 114.95 & 96.65 & 231.8 & 188.6 \\
$\mathbf{4}$ & 1.905 & 0.009 & 8.85 & 9.22 & 19.33 & 19.83 & 38.09 & 39.57 & 148.33 & 157.4 & 290.45 & 311.7 \\
\hline
\end{tabular}

Legend: Obs. $=$ Observed service time

Pred. $=$ Predicted service time (using the developed BDST models)

Table 4: Chi-Square test results on various breakthrough concentrations

\begin{tabular}{lllllll}
\hline $\mathbf{H}(\mathbf{m})$ & $\mathbf{1 0} \%$ & $\mathbf{4 0} \%$ & $\mathbf{5 0} \%$ & $\mathbf{6 0} \%$ & $\mathbf{8 0} \%$ & $\mathbf{9 0} \%$ \\
\hline 3 & 0.017 & $0-032$ & 0.043 & 0.199 & 2.302 & 6.95 \\
3.5 & 0.048 & 0.077 & 0.087 & 0.345 & 3.465 & 9.9 \\
4 & 0.009 & 0.015 & 0.013 & 0.055 & 0.522 & 1.45 \\
$\boldsymbol{\chi}^{2}$ & $\mathbf{0 . 0 7 4}$ & $\mathbf{0 . 1 2 4}$ & $\mathbf{0 . 1 4 3}$ & $\mathbf{0 . 5 9 9}$ & $\mathbf{6 . 2 8 9}$ & $\mathbf{1 8 . 3}$ \\
\hline
\end{tabular}

$N B \quad$ (i) Degree of freedom $=3-1=2$

(ii) Chi-square values from Frank and Altheon (1994) are 5.99 and $\mathbf{9 . 2 1}$ at 5\% and $1 \%$ significant levels respectively. 


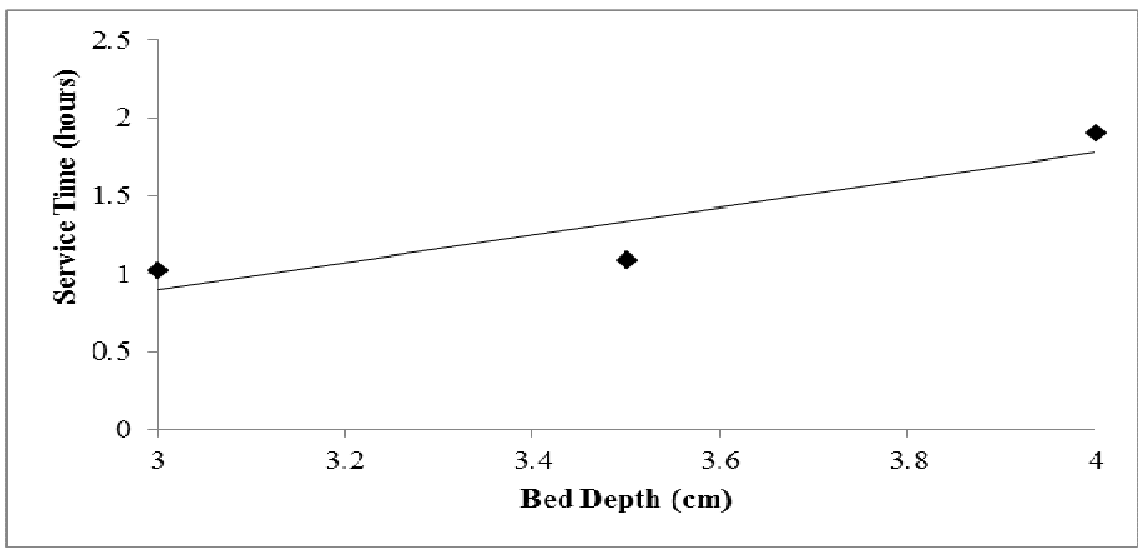

Fig. 7 : BDST plots at $10 \%$ breakthrough

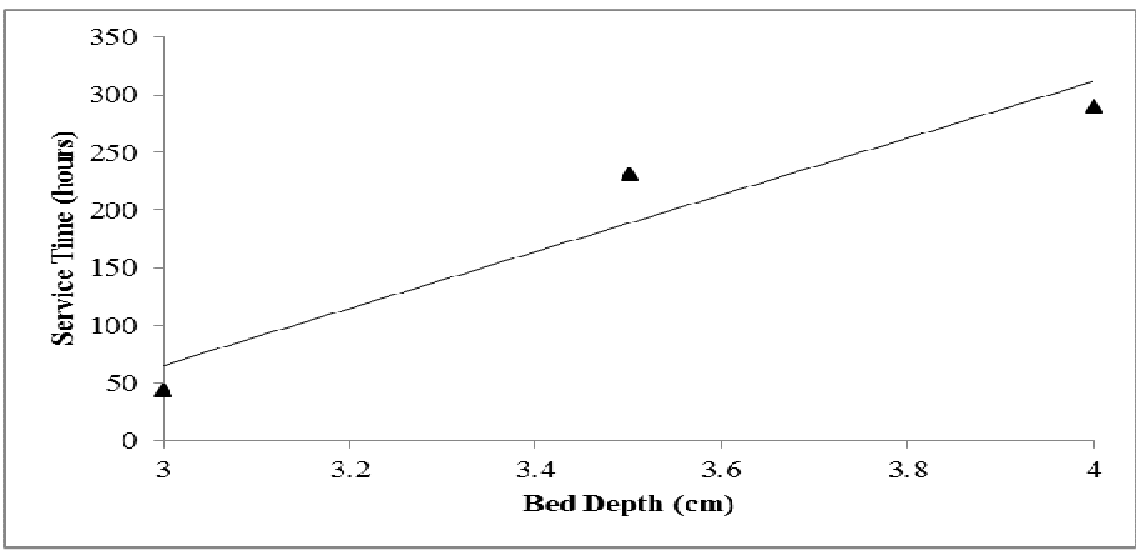

Fig. 8 : BDST plots at $90 \%$ breakthrough

through from test column is (Table 2): $\mathrm{t}=0.883 \mathrm{H}-1.752$

The diameter of the test column is $4 \mathrm{~cm}$, therefore for a flow rate of $1.61 \mathrm{~L} / \mathrm{h}$, the hydraulic loading rate $=$

$$
\begin{aligned}
\frac{\mathrm{Q}}{\mathrm{A}}=\frac{1.61 \times 10^{-3} \times 4}{3.142 \times 004^{2}}\left(\mathrm{~m}^{3} / \mathrm{m}^{2} / \mathrm{h}\right) \\
=1.281\left(\mathrm{~m}^{3} / \mathrm{m}^{2} / \mathrm{h}\right)
\end{aligned}
$$

$125 \mathrm{~m}^{3} / \mathrm{h}\left(=1000 \mathrm{~m}^{3} / 8\right.$-hour day $)=159.134\left(\mathrm{~m}^{3} /\right.$ $\left.\mathrm{m}^{2} / \mathrm{h}\right)$.

The change in flow rate will cause a change in slope.

The new slope, $a^{1}=\frac{1.281}{159.134} \times 0.883=0.007108$

Assume design column diameter of $1000 \mathrm{~mm}$, Thus, the BDST model for the design column then hydrulic loading rate for the flow rate of is: 
Table 5 : Predicted BDST constants for other flow rates

\begin{tabular}{llllll}
\hline $\begin{array}{l}\text { Breakthrough } \\
(\%)\end{array}$ & $\mathbf{Q}^{\mathbf{1}}(\mathbf{L} / \mathbf{h})$ & $\mathbf{a}$ & $\mathbf{a}^{\mathbf{l}}$ & ${\mathbf{b}=\mathbf{b}^{\mathbf{l}}}$ & $\mathbf{t}_{\mathbf{c}}(\mathbf{h})$ \\
\hline 10 & & & & & \\
& 0.5 & 0.833 & 2.844 & -1.752 & 9.624 \\
& 1 & 0.833 & 1.422 & -1.752 & 3.936 \\
& 2 & 0.833 & 0.711 & -1.752 & 1.092 \\
& 3 & 0.833 & 0.474 & -1.752 & 0.144 \\
90 & 5 & 0.833 & 0.284 & -1.752 & -0.616 \\
& 0.5 & 246.2 & 792.764 & -673.1 & 2497.956 \\
& 1 & 246.2 & 396.382 & -673.1 & 912.428 \\
& 2 & 246.2 & 198.191 & -673.1 & 119.664 \\
& 3 & 246.2 & 132.127 & -673.1 & -144.592 \\
& 5 & 246.2 & 79.276 & -673.1 & -355.996 \\
\hline
\end{tabular}

Table 6: Predicted BDST constants for other initial chromium concentrations

\begin{tabular}{lllllll}
\hline $\begin{array}{l}\text { Breakthrough } \\
(\%)\end{array}$ & $\mathbf{C}^{\mathbf{1}}(\mathbf{m g} / \mathbf{L})$ & $\mathbf{a}$ & $\mathbf{a}^{\mathbf{1}}$ & $\mathbf{b}$ & $\mathbf{b}^{\mathbf{1}}$ & $\mathbf{t}_{\mathbf{c}}(\mathbf{h})$ \\
\hline 10 & 1.2 & 0.833 & 2.319 & -1.752 & -4.60 & 4.676 \\
& 1.5 & 0.833 & 1.855 & -1.752 & -3.68 & 3.74 \\
& 2 & 0.833 & 1.391 & -1.752 & -2.760 & 2.804 \\
& 3 & 0.833 & 0.927 & -1.752 & -1.840 & 1.868 \\
& 5 & 0.833 & 0.556 & -1.752 & -1.104 & 1.12 \\
90 & 7 & 0.833 & 0.397 & -1.752 & -0.789 & 0.799 \\
& 1.2 & 246.2 & 646.48 & -673.1 & -1767.47 & 818.45 \\
& 1.5 & 246.2 & 517.184 & -673.1 & -1413.96 & 654.777 \\
& 2 & 246.2 & 387.888 & -673.1 & -1060.47 & 491.083 \\
& 3 & 246.2 & 258.592 & -673.1 & -706.979 & 327.389 \\
& 5 & 246.2 & 155.155 & -673.1 & -424.188 & 196.432 \\
& 7 & 246.2 & 110.825 & -673.1 & -302.991 & 140.309 \\
\hline
\end{tabular}

$\mathrm{t}=0.007108 \mathrm{H}-1.752$

But $\mathrm{t}=8 \mathrm{~h}$

Therefore, $\mathrm{H}=(8+1.752) / 0.007108=$ Bed depth $=14 \mathrm{~m}$ $1372 \mathrm{~cm}=13.72 \mathrm{~m}$.
Hence the specifications of the design column are :

Diameter $=1000 \mathrm{~mm}$

Hydrualic loading rate $=159.134 \mathrm{~m}^{3} / \mathrm{m}^{2} / \mathrm{h}$ 
Service time $=8$ hours

It should be borne in mind that the data used in constructing BDST models herein, were obtained using simulated solutions instead of live wastewater. Impurities in industrial effluents could interfere with the adsorption of chromium and consequently result in an inaccurate prediction in treatment of industrial effluents. Hence the need for pilot studies on live wastewater.

\section{CONCLUSION}

The effects of time and carbon height on chromium removal from water were investigated in fixed down flow adsorption columns. There was a gradual decrease in the percentage of chromium adsorbed with time. The percentage adsorbed became zero at $72.33,467.5$ and 572 hours respectively for $3 \mathrm{~cm}, 3.5 \mathrm{~cm}$ and $4 \mathrm{~cm}$ carbon heights. These results showed that chromium removal was significantly affected by both carbon height and service time. The breakthrough curves for chromium adsorption deviated from the characteristic S-curve for most dynamic studies. This is because $100 \%$ chromium removal was not attained even at the commencement of the experiment when all the adsorption sites were available due to the high initial concentration of the adsorbate adopted in this study. The Hutchins (1973) BDST model was used to study the columns performance at different breakthrough concentrations. The BDST rate constant $\mathrm{k}_{\mathrm{a}}$, decreased, while adsorption capacity of the bed per unit volume, $\mathrm{N}_{\mathrm{o}}$, and the critical bed depth, $\mathrm{H}_{\mathrm{o}}$, increased with increase in breakthrough percentage. The BDST equation obtained at flow rate of $1.61 \mathrm{~L} /$ $\mathrm{hr}$ and influent chromium concentration of $3.151 \mathrm{mg} / \mathrm{L}$ was used to predict the adsorbent performance at other flow rates and initial chromium concentrations. It was observed that for a given breakthrough concentration, the service time decreased with increase in both flow rate and initial concentration. Chi-square test performed to verify the validity of the developed BDST models revealed that the models predicted the columns performance better at lower breakthrough concentrations. It was recommended that MSSAC can be used for the removal of chromium from wastewater in adsorption columns; however there is need for pilot studies on live wastewater to investigate the effect of interference.

\section{REFERENCES}

Akpen, G. D., Nwaogazie, I. L. and Leton, T. G. (2011). "Optimum Conditions for the Removal of Colour from Wastewater by Mango Seed Shell based Activated Carbon", Indian Journal of Science and Technology, 4 (8): 890-894

Akpen, G. D. (2011). "Mango Seed Shell Based Activated Carbon for Wastewater Treatment. PhD Thesis, Department of Civil and Environmental Engineering, University of Port Harcourt, Port Harcourt, Nigeria.

Akpen, G. D. (2012). Mango Seed Shell Activated Carbon for Wastewater Treatment, Lambert Academic Publishing $\mathrm{GmbH}$ and Co. KG, Germany

Akpen, G. D., Nwaogazie, I. L. and Leton, T. G. (2014). "Adsorption Characteristics of Mango (magnifera indica) Seed Shell Activated Carbon for Removing Phenol from Wastewater," Journal of Applied Science and Technology (JAST), 19(1\&2): 43-48. http:// www.ajol.info.

Bohart, G. S. and Adams, E. Q. (1920). "Some Aspects of the Behaviour of Charcoal with respect to Chlorine", Journal of Chemical Society., 42:523-544.

Eckenfelder, W. W. (1989). Industrial Water Pollution Control. $2^{\text {nd }}$ edition, McGraw-Hill Book Co. Singapore: 263-290.

Frank, H. and Altheon, S. C.(1994). Statistics -Concepts and Applications, Low Price Edition, Cambridge University Press, Great Britain”, Environ. Eng. Res., 13(2): 79-84. 


\section{Akpen et al.}

Mazumder, D., Ghosh, D. and Bandyopadhyay, P. (2011). "Treatment of Electroplating Wastewater by Adsorption Technique", International Journal of Civil and Environmental Engineering, 3(2): 101-110.

McKay, G. and Bino,M. J. (1990): "Fixed Bed Adsorption for the Removal of Pollutants from Water", Environmental Pollution, 66: $33-53$

Michaels, A. S. (1952). "Simplified Method of Interpreting Kinetic Data in FluidBed Ion Exchange", Ind. Eng. Chem., 44: 19-22.

Saner, G. (1980). Chromium in Nutrition and
Diseases. Alan Liss Inc., New York

Thomas, H. C. (1948). "Heterogeneous Ion Exchange in a Flowing System", J. Am. Chem. Soc. 66: 1466-1664.

WHO, (1988). Environmental Health Criteria 61, Chromium. World Health Organization, Geneva.

Zhao, M. and Duncan, J. R. (1998). "Bed-depth Service Time Analysis on Column Removal of $\mathrm{Zn}^{2+}$ using Azolla filliculoides", Biotechnology Letters, 20: 37-39. 